\title{
Reactivity of $\mathrm{O}_{2}$ on $\mathrm{Pd} / \mathrm{Ru}(0001)$ and $\mathrm{PdRu} / \mathrm{Ru}(0001)$ surface alloys
}

\author{
D. Farías, ${ }^{1,2,3}$ M. Minniti, ${ }^{1,4}$ and R. Miranda ${ }^{1,2,3,4}$ \\ ${ }^{1}$ Departamento de Física de la Materia Condensada, Universidad Autónoma de Madrid, 28049 Madrid, Spain \\ ${ }^{2}$ Instituto "Nicolás Cabrera," Universidad Autónoma de Madrid, 28049 Madrid, Spain \\ ${ }^{3}$ Condensed Matter Physics Center (IFIMAC), Universidad Autónoma de Madrid, 28049 Madrid, Spain \\ ${ }^{4}$ Instituto Madrileño de Estudios Avanzados en Nanociencia (IMDEA-Nanociencia), 28049 Madrid, Spain
}

(Received 3 March 2017; accepted 5 May 2017; published online 24 May 2017)

\begin{abstract}
The reactivity of a $\mathrm{Pd}$ monolayer epitaxially grown on $\mathrm{Ru}(0001)$ toward $\mathrm{O}_{2}$ has been investigated by molecular beam techniques. $\mathrm{O}_{2}$ initial sticking coefficients were determined using the King and Wells method in the incident energy range of $40-450 \mathrm{meV}$ and for sample temperatures of $100 \mathrm{~K}$ and $300 \mathrm{~K}$, and compared to the corresponding values measured on the clean $\mathrm{Ru}(0001)$ and $\mathrm{Pd}(111)$ surfaces. In contrast to the high reactivity shown by $\mathrm{Ru}(0001)$ at $100 \mathrm{~K}$, the $\mathrm{Pd} / \mathrm{Ru}(0001)$ system exhibits a monotonic decrease in the sticking probability of $\mathrm{O}_{2}$ as a function of normal incident energy. At room temperature, the system was found to be inert. Thermal desorption measurements show that $\mathrm{O}_{2}$ is adsorbed molecularly at $100 \mathrm{~K}$. A completely different behaviour has been measured for the $\mathrm{Pd}_{0.95} \mathrm{Ru}_{0.05} / \mathrm{Ru}(0001)$ surface alloy. On this surface, the $\mathrm{O}_{2}$ sticking probability increases with incident energy and resembles the one observed on the clean $\mathrm{Ru}(0001)$ surface, even at $300 \mathrm{~K}$. Thermal desorption measurements point to dissociative adsorption of $\mathrm{O}_{2}$ in this system. Both the charge transfer from the $\mathrm{Pd}$ to the $\mathrm{Ru}$ substrate and the compressive strain on the $\mathrm{Pd}$ monolayer contribute to decrease in the reactivity of the $\mathrm{Pd} / \mathrm{Ru}(0001)$ system well below those of both $\mathrm{Ru}(0001)$ and Pd(111). Published by AIP Publishing. [http://dx.doi.org/10.1063/1.4983994]
\end{abstract}

\section{INTRODUCTION}

Varying the catalytic activity of a surface in a controlled way can be generally achieved through different routes. A first approach consists in the modification of the lateral lattice constant of a given metal layer by growing pseudomorphic monolayers (MLs) of that metal on top of a substrate with a different lattice constant. This will introduce a tensile strain if the lattice parameter of the substrate is larger than that of the deposited metal [i.e., $\mathrm{Cu}$ on $\mathrm{Ru}(0001)$ ] or a compressive strain if the lattice constant of the deposited metal is smaller than the one of the substrate [i.e., $\mathrm{Pd}$ on $\mathrm{Ru}(0001)]$. Strain is known to strongly influence the surface reactivity, ${ }^{1}$ with a tensile (compressive) strain inducing an upshift (downshift) of the d-band center and a corresponding enhancement (decrease) of the adsorption energy. ${ }^{2-6}$ This approach of growing metal layers epitaxially onto single-crystal metal substrates with different lattice constants has been demonstrated to result in very efficient selective catalysts in reactions involving $\mathrm{H}_{2}$ molecules. ${ }^{7}$ A second route involves the formation of well controlled surface alloys, which often exhibit geometrical and electronic properties differing deeply from those of their constituent materials. ${ }^{8-14}$ As an example, recent studies have shown that small amounts of Pd atoms alloyed into the $\mathrm{Cu}$ (111) surface strongly reduce the dissociation barrier for $\mathrm{H}_{2}$ on $\mathrm{Cu}(111)$ and can efficiently dissociate $\mathrm{H}_{2}$ molecules, allowing them to spill over onto the host metal. ${ }^{15,16} \mathrm{~A}$ third route has been explored more recently and consists in controlling in an efficient way, using curved crystals and stepped surfaces, the type and density of steps present on a given surface. ${ }^{17-20}$
The interaction of $\mathrm{O}_{2}$ molecules with surfaces is a particularly interesting system, since the adsorption of oxygen is notoriously difficult to model because, in contrast to the case of $\mathrm{H}_{2},{ }^{21}$ it is generally believed that non-adiabatic transitions should be included in the calculations. ${ }^{22}$ Only recently, the experimental sticking coefficient of $\mathrm{O}_{2}$ on the $\mathrm{Al}(111)$ surface ${ }^{23}$ has been theoretically reproduced by including multiple Potential Energy Surfaces (PESs) associated with different spin configurations in the dynamics. ${ }^{24,25}$ To further test the validity of the calculated PESs, new experimental data on the dissociation dynamics of $\mathrm{O}_{2}$ on a range of transition metal surfaces are badly needed.

In this respect, exploring the reactivity toward $\mathrm{O}_{2}$ of the system formed by one monolayer (ML) of Pd grown epitaxially on $\mathrm{Ru}(0001)$ is quite interesting, since the first Pd layer grows pseudomorphically on $\mathrm{Ru}(0001)^{26,28-30}$ adopting the nearest neighbour distance of the substrate $(2.65 \AA)$, i.e., laterally compressed by $3.6 \%$ with respect to the $\operatorname{Pd}(111)$ surface. Hartmann et al. ${ }^{11}$ have shown that deuterium molecules stick on this surface with a probability of 0.05 , which is a factor of four smaller than the one measured on clean $\mathrm{Ru}(0001)$. Also the adsorption of $\mathrm{CO}$ is weaker on the $\mathrm{Pd} / \mathrm{Ru}(0001)$ system than that on $\operatorname{Pd}(111)$ or $\operatorname{Ru}(0001) .^{26,27}$

In the present work, we explore the first two routes mentioned above by reporting measurements of the $\mathrm{O}_{2}$ dissociation probabilities on the pseudomorphic monolayer of $\mathrm{Pd} / \mathrm{Ru}(0001)$ and the surface alloy $\mathrm{Pd}_{0.95} \mathrm{Ru}_{0.05} / \mathrm{Ru}(0001)$ as a function of the incident energy of the oxygen molecules and the surface temperature. The measurements have been performed using the King and Wells method, ${ }^{31}$ whereby the kinetic energy of the molecular beam has been varied between 
40 and $450 \mathrm{meV}$. At $100 \mathrm{~K}$ and for all impinging energies, the monolayer $\mathrm{Pd} / \mathrm{Ru}(0001)$ presents a much lower initial sticking probability for $\mathrm{O}_{2}$ as compared to the one observed on both clean $\mathrm{Ru}(0001)$ and $\mathrm{Pd}(111)$. At $300 \mathrm{~K}$, the $\mathrm{Pd} / \mathrm{Ru}(0001)$ surface was found to be completely inert to $\mathrm{O}_{2}$, again in sharp contrast with both $\mathrm{Ru}(0001)$ and $\mathrm{Pd}(111)$. Thermal desorption spectroscopy (TDS) suggests that $\mathrm{O}_{2}$ is adsorbed molecularly on the monolayer $\mathrm{Pd} / \mathrm{Ru}(0001)$ system. A different behaviour has been observed on the $\mathrm{Pd}_{0.95} \mathrm{Ru}_{0.05} / \mathrm{Ru}(0001)$ surface alloy, which presents a high reactivity to $\mathrm{O}_{2}$, even at room temperature. No $\mathrm{O}_{2}$ desorption peak was observed in TDS below $300 \mathrm{~K}$, which suggests the dissociative adsorption of oxygen on the PdRu surface alloy.

\section{EXPERIMENTAL DETAILS}

Experiments have been carried out in a Helium Atom Scattering (HAS) apparatus described elsewhere. ${ }^{32}$ It consists of a three-stage differentially pumped beam system and an 18 in. diameter UHV scattering chamber. The free jet expansion is produced through a nozzle of $d=10 \mu \mathrm{m}$ diameter. The nozzle temperature $T_{n}$ can be varied between 100 and $700 \mathrm{~K}$. The angular distribution of the scattered atoms is measured with a quadrupole mass spectrometer mounted on a two-axis goniometer. The base pressure in the scattering chamber is typically $5 \times 10^{-10}$ mbar. The sample holder allows heating the crystal to $1500 \mathrm{~K}$ and cooling to $100 \mathrm{~K}$. The sample temperature was measured with a type $\mathrm{C}$ thermocouple spotwelded to the sample. Details on $\mathrm{Ru}(0001)$ surface preparation can be found elsewhere. ${ }^{33}$ Surface cleanliness and order of the $\mathrm{Ru}(0001)$ surface were checked using low-energy electron diffraction (LEED) and helium diffraction. ${ }^{34}$

$\mathrm{O}_{2}$ incident kinetic energies have been varied between 40 and $450 \mathrm{meV}$. They were controlled by seeding oxygen in a carrier gas (either $\mathrm{Ne}$ or $\mathrm{He}$ ) and varying the oxygen concentration and the nozzle temperature. Since this HAS apparatus is not equipped with a time-of-flight system, the mean translational energy of the incoming $\mathrm{O}_{2}$ molecules has been estimated as follows: ${ }^{35}$

$$
E_{T}=\left[(1-x) \frac{m}{M}+x\right]^{-1} C_{p} T_{n},
$$

where $m$ and $M$ are the molecular weights of the light and heavy gas, respectively, $x$ is the mole fraction of the heavy gas, $C_{p}$ is the mean heat capacity averaged according to gas concentrations, and $T_{n}$ is the nozzle temperature. The uncertainty on the incident beam energy is estimated to be $10 \%$ of its mean value.

The HAS apparatus used in the current study has recently been modified ${ }^{36}$ to allow sticking measurements using the King and Wells method. ${ }^{31}$ These measurements have been performed at an angle of incidence $\Theta_{i}=15^{\circ}$, which is the smallest angle, which allows the detection of specular diffraction, owing to its limitations in the mechanism used for rotating the detector. It is worth emphasizing that the quality of the He beam (concerning angular divergence and energy spread) employed in the sticking experiments is the same as that usually employed for $\mathrm{He}$ and $\mathrm{H}_{2}$ diffraction measurements using the same apparatus. ${ }^{37}$
Pd was deposited from a commercial evaporator equipped with a Pd rod. The $\mathrm{Ru}(0001)$ crystal was kept at $700 \mathrm{~K}$ during film growth in order to avoid surface alloying, which starts around $850 \mathrm{~K} .^{28}$ The deposited coverage and the structural quality of the epitaxial Pd layer have been checked by monitoring the changes in the intensity of the specular He beam, taking advantage of its high sensitivity to surface defects ${ }^{34,38}$ and the oscillatory behaviour with monolayer periodicity characteristic of systems that grow layer by layer. ${ }^{39}$ A typical deposition curve is shown in Fig. 1. The observation of a clear maximum corresponds to the completion of the first Pd epitaxial layer. As it can be seen from Fig. 1, the first maximum in the reflected He-intensity occurred after about $40 \mathrm{~min}$, corresponding to an evaporation rate of $\sim 0.03 \mathrm{ML} / \mathrm{min}$. Therefore, the HAS technique allows the growth of Pd monolayers to be monitored with a daily precision of $1 \%$. The $\mathrm{Cu}$ monolayer was grown by the same procedure, keeping the $\mathrm{Ru}(0001)$ crystal at $500 \mathrm{~K}$ during $\mathrm{Cu}$ evaporation. ${ }^{36}$

$\mathrm{The} \mathrm{Pd}_{0.95} \mathrm{Ru}_{0.05} / \mathrm{Ru}(0001)$ surface alloy was prepared by depositing $0.95 \mathrm{ML}$ Pd at $300 \mathrm{~K}$ (just before the HAS maximum) followed by annealing at $1150 \mathrm{~K}$. We took advantage of the fact that Hartmann et al. ${ }^{11}$ have shown that annealing a certain amount of $\mathrm{Pd}$ on $\mathrm{Ru}(0001)$ to $1150 \mathrm{~K}$ results in the formation of a surface alloy with a negligible loss of Pd atoms from the surface. Thus, significant desorption or diffusion into the bulk can be excluded. This preparation method has been checked in our HAS system by performing $\mathrm{H}_{2}$ sticking measurements. The results (summarized in Ref. 40) show that the same step-like dependence of the initial reactive sticking probability as a function of $\mathrm{Pd}$ concentration is observed in both experiments, with a sharp increase in reactivity for a $\mathrm{Ru}$ concentration of $5 \%$. Thus, we can conclude that the alloy composition is essentially the same as the one reported in Ref. 11. Furthermore, as established by Hartmann et al. ${ }^{11}$,

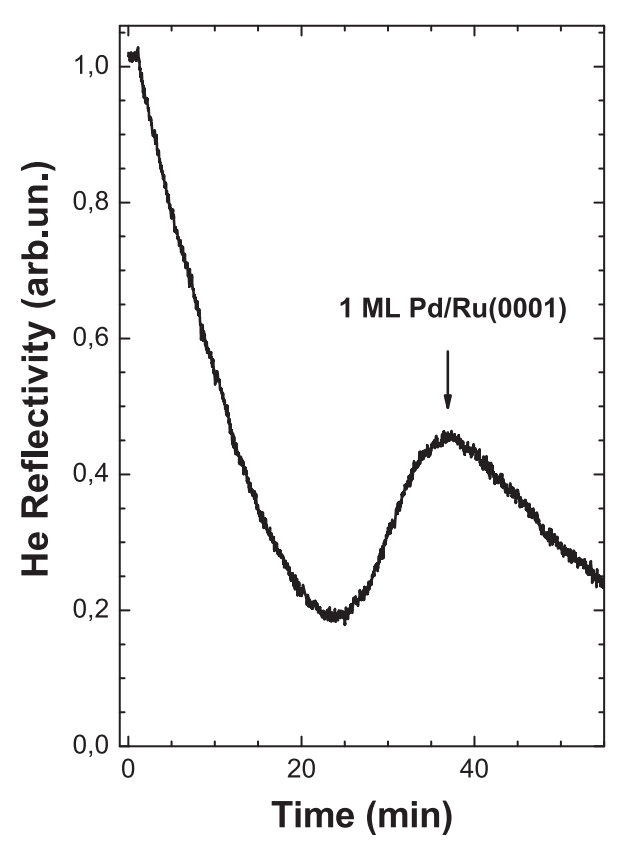

FIG. 1. Evolution of the intensity of the specular He beam during Pd evaporation on $\mathrm{Ru}(0001)$ as a function of time at a surface temperature of $700 \mathrm{~K}$. The evaporation rate is $\sim 0.03 \mathrm{ML} / \mathrm{min}$. The maximum indicates the completion of the first monolayer. 
the system of interest is actually the one containing just 5\% $\mathrm{Ru}$; at higher $\mathrm{Ru}$ coverages, the system behaves as pure $\mathrm{Ru}$ from the viewpoint of $\mathrm{H}_{2}$ and $\mathrm{O}_{2}$ sticking. For this reason, all results reported for the alloy refer to the $\mathrm{Pd}_{0.95} \mathrm{Ru}_{0.05} / \mathrm{Ru}(0001)$ surface.

\section{RESULTS}

Figure 2 shows the initial sticking coefficient as a function of the normal energy of the oxygen molecules, $E_{n}=E_{i} \cos ^{2} \theta_{i}$, for the clean $\mathrm{Ru}(0001)$ surface, the pseudomorphic, compressed ML Pd/Ru(0001), and the pseudomorphic, expanded $\mathrm{ML} \mathrm{Cu} / \mathrm{Ru}(0001)$ measured at $100 \mathrm{~K}$. For comparison, data for the clean $\operatorname{Pd}(111)$ surface from Ref. 41 are also shown. On the pristine $\mathrm{Ru}(0001)$ surface, at $100 \mathrm{~K}$, the initial dissociative adsorption probability, $S_{0}$, decreases sharply with increasing incident normal energies, passes through a minimum around $80 \mathrm{meV}$, and increases again with the incident energy, until it saturates at about $500 \mathrm{meV}$. This is in agreement with the previous results reported in Ref. 42. This behaviour is indicative of a trapping-mediated mechanism into a physisorbed precursor state quickly followed by a temperature dependent kinetic competition between desorption and thermal dissociation. However, EELS and TPD studies yielded no evidence, at low coverages, for a stable molecularly chemisorbed state of oxygen on clean $\mathrm{Ru}(0001)$ at surface temperatures as low as $30 \mathrm{~K}^{43}$ At higher normal energies, the adsorption probability increases with energy, which is consistent with a direct dissociation mechanism dominated by the charge transfer from the substrate. At room temperature, in the low normal energy regime, there is a strong decrease in the initial sticking coefficient (see Fig. 3). This dependence of $S_{0}$ with the surface temperature confirms the existence of a precursor-mediated

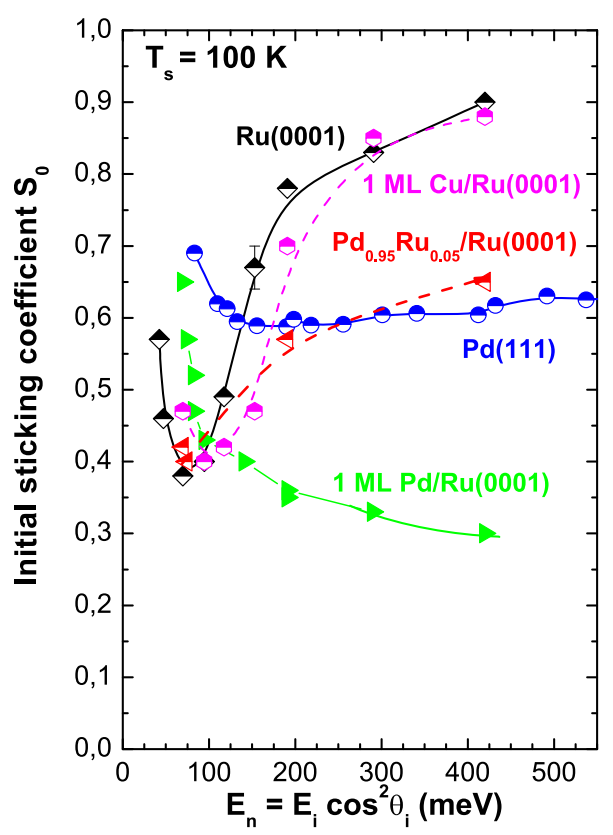

FIG. 2. Initial sticking probability of $\mathrm{O}_{2}$ versus the normal energy of the incident beam for clean $\mathrm{Ru}(0001), 1 \mathrm{ML} \mathrm{Pd} / \mathrm{Ru}(0001), 1 \mathrm{ML} \mathrm{Cu} / \mathrm{Ru}(0001)$ surfaces and the $\mathrm{Pd}_{0.95} \mathrm{Ru}_{0.05} / \mathrm{Ru}(0001)$ surface alloy. The sample temperature is $100 \mathrm{~K}$. The data for clean $\operatorname{Pd}(111)$ are from Ref. 41. The experimental error in sticking probabilities is estimated as \pm 0.03 . Lines are a guide to the eye.

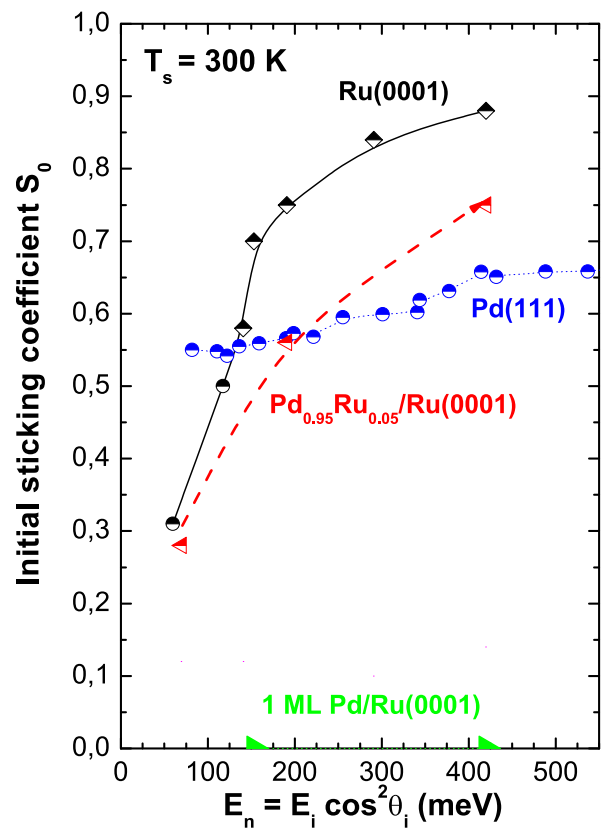

FIG. 3. Initial sticking probability of $\mathrm{O}_{2}$ versus incident beam normal energy for clean $\mathrm{Ru}(0001)$, $1 \mathrm{ML} \mathrm{Pd} / \mathrm{Ru}(0001)$, and the $\mathrm{Pd}_{0.95} \mathrm{Ru}_{0.05} / \mathrm{Ru}(0001)$ surface alloy. The sample temperature is $300 \mathrm{~K}$. The data for clean $\operatorname{Pd}(111)$ from Ref. 41 are also shown. Lines are a guide to the eye.

mechanism which becomes active for molecules impinging on the surface at low kinetic energy. In the high kinetic energy regime, the authors of Ref. 42 observed that the dissociative chemisorption probability, $S_{0}$, increases with the surface temperature. This tendency is consistent with, but not clearly visible in our results at $300 \mathrm{~K}$.

The data corresponding to the expanded $\mathrm{ML} \mathrm{Cu} / \mathrm{Ru}(0001)$ reveal that the oxygen sticking probability at $T_{s}=100 \mathrm{~K}$ closely follows the one measured for clean $\mathrm{Ru}(0001)$ in the full energy range studied, a behaviour observed previously at $300 \mathrm{~K}^{36}$ Our current data prove that this similarity includes the low kinetic energy behaviour, indicating that the trapping-assisted adsorption is also operative in the ML $\mathrm{Cu} / \mathrm{Ru}(0001)$. Whether this mechanism leads to a stable molecularly chemisorbed state of $\mathrm{O}_{2}$ on this surface [in contrast to clean $\mathrm{Ru}(0001)]$ is something that cannot be answered based on our current experimental data. However, our results clearly show that the ML $\mathrm{Cu}$ under tensile strain on $\mathrm{Ru}(0001)$ is much more reactive than $\mathrm{Cu}(111)$. Contrary to the observations on $\mathrm{Ru}(0001)$, our previous study ${ }^{36}$ has shown also that the expanded $\mathrm{ML} \mathrm{Cu} / \mathrm{Ru}(0001)$ surface is fully passivated toward $\mathrm{H}_{2}$, even at relatively high incident energies ( $175 \mathrm{meV}$ ). This further allows us to exclude the existence of uncovered $\mathrm{Ru}$ islands in our system as the possible source of the high reactivity toward $\mathrm{O}_{2}$ observed in the current results for $\mathrm{ML}$ $\mathrm{Cu} / \mathrm{Ru}(0001)$ (see below).

Also shown in Fig. 2 are the results for clean $\operatorname{Pd}(111)$ taken from Ref. 41. On $\mathrm{Pd}(111)$, the adsorption of $\mathrm{O}_{2}$ shows an initial sticking coefficient that corresponds to a molecular precursor dissociation mechanism over the entire translational energy range. At low kinetic energies, $S_{0}$ decreases with increasing normal energy and the molecular precursor is populated either directly or via a trapped physisorbed state, while at high kinetic energies, direct adsorption into 
a chemisorbed molecular precursor state takes place before dissociation. $^{41}$

For the ML Pd/Ru(0001) at $T_{s}=100 \mathrm{~K}$, a sharp decrease in the oxygen sticking probability with the incident energy is observed at energies below $130 \mathrm{meV}$. This behavior suggests the existence of trapping into a molecular physisorbed well. In the high kinetic energy regime, the adsorption probability drops continuously with increasing translational energy, and the measured sticking probabilities are substantially lower than the ones observed on the clean $\mathrm{Ru}(0001)$ surface and approximately half of those obtained on $\operatorname{Pd}(111)$.

Figure 3 shows the initial sticking coefficient results for the clean $\mathrm{Ru}(0001)$ surface and the $\mathrm{ML} \mathrm{Pd} / \mathrm{Ru}(0001)$, measured at $T_{s}=300 \mathrm{~K}$. For $\operatorname{Pd}(111)$, the sticking curve shows the same quantitative features as at $T_{s}=100 \mathrm{~K}$, except for a steeper increase at higher translational energies. ${ }^{41}$ A quite different behaviour has been observed for the ML Pd/Ru(0001), which was found to be completely inert at room temperature, the initial sticking coefficient being below the detection limit of the King and Wells technique ( $S_{0}$ below 0.01 ). This is in agreement with the XPS measurements showing this surface to be inert to the background oxygen at room temperature. ${ }^{30}$ The behaviour of the $\operatorname{Pd}(111)$ surface is a consequence of the dissociative chemisorption of $\mathrm{O}_{2} \cdot{ }^{41,44}$ On the ML $\mathrm{Pd} / \mathrm{Ru}(0001)$ surface, in contrast, our data suggest that this process is energetically forbidden at $300 \mathrm{~K}$. It should be noted that the reactivity of the $\mathrm{Pd}_{0.95} \mathrm{Ru}_{0.05} / \mathrm{Ru}(0001)$ surface alloy increases drastically in comparison to the $\mathrm{ML} \mathrm{Pd} / \mathrm{Ru}(0001)$, both at $300 \mathrm{~K}$ and $100 \mathrm{~K}$. At room temperature, in contrast to the inert ML $\mathrm{Pd} / \mathrm{Ru}(0001)$ surface, the PdRu alloy presents reactivity to oxygen which resembles in trend with energy and absolute values the one measured on clean $\mathrm{Ru}(0001)$. These results show that the presence of a small percentage of Ru atoms on the surface completely changes the dynamics of the interaction between the oxygen molecules and the substrate.

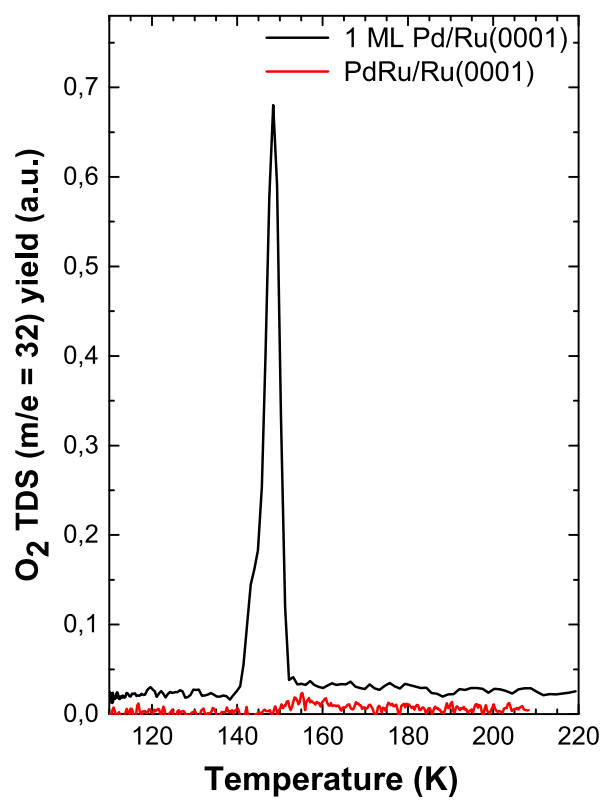

FIG. 4. Thermal desorption spectra of $\mathrm{O}_{2}$ from $1 \mathrm{ML} \mathrm{Pd} / \mathrm{Ru}(0001)$ and the $\mathrm{Pd}_{0.95} \mathrm{Ru}_{0.05} / \mathrm{Ru}(0001)$ surface alloy. The desorption peak observed at 145 $\mathrm{K}$ suggests that the adsorption is non-dissociative on the ML $\mathrm{Pd} / \mathrm{Ru}(0001)$ surface at $100 \mathrm{~K}$. The curves are shifted vertically for clarity.
To get more insight into the oxygen adsorption mechanism, we have performed thermal desorption measurements after $\mathrm{O}_{2}$ exposure. The results are presented in Fig. 4. For the $\mathrm{ML} \mathrm{Pd} / \mathrm{Ru}(0001)$, an $\mathrm{O}_{2}$ desorption peak appears at about $145 \mathrm{~K}$ after heating a surface previously saturated with the oxygen beam at $E_{i}=450 \mathrm{meV}$ and $T_{s}=110 \mathrm{~K}$. On the $\mathrm{Pd}_{0.95} \mathrm{Ru}_{0.05} / \mathrm{Ru}(0001)$ alloy surface, in contrast, this peak is much smaller and shifted to $155 \mathrm{~K}$ after performing the same experiment. For the $\mathrm{O}_{2} / \mathrm{Pd}(111)$ system, molecular desorption occurs at $150 \mathrm{~K}$ and $200 \mathrm{~K} .{ }^{44}$ Thus, the peak at $145 \mathrm{~K}$ in our current study resembles the first molecular adsorption peak on $\operatorname{Pd}(111)$, whereas no evidence was observed for the second peak at $200 \mathrm{~K}$. These data suggest that $\mathrm{O}_{2}$ adsorbs molecularly on the $\mathrm{ML} \mathrm{Pd} / \mathrm{Ru}(0001)$, desorbing at $145 \mathrm{~K}$, although dissociation might take place simultaneously to molecular desorption. This also explains the observation of zero initial sticking at $300 \mathrm{~K}$ on this system. On the $\mathrm{Pd}_{0.95} \mathrm{Ru}_{0.05} / \mathrm{Ru}(0001)$ surface alloy, the quite small $\mathrm{O}_{2}$ desorption peak observed after heating points to the occurrence of dissociative adsorption on this surface when exposed to $\mathrm{O}_{2}$ even at $100 \mathrm{~K}$. The small desorption feature at $155 \mathrm{~K}$ could be due to the desorption of molecularly adsorbed $\mathrm{O}_{2}$ from large $\mathrm{Pd}$ areas on the alloyed surface.

\section{DISCUSSION}

The current experimental results for the $\mathrm{ML} \mathrm{Pd} / \mathrm{Ru}(0001)$ and the $\mathrm{ML} \mathrm{Cu} / \mathrm{Ru}(0001)$ systems follow the predictions of the d-band model, which correlates the position of the d-band center with respect to the Fermi level to the chemical reactivity. ${ }^{45}$ According to this model, the farther (closer) the center of the $\mathrm{d}$ bands is from the Fermi level, the smaller (larger) is the chemisorption energy. ${ }^{2,3,45,46}$ The $\mathrm{d}$ bands are narrow, and small changes in the environment (strain, interaction with the substrate, etc.) can modify significantly the energy location of the $d$ states and their interaction with adsorbate states.

The Pd monolayer grows pseudomorphically on $\mathrm{Ru}(0001)$ and is, therefore, laterally compressed by $3.6 \%$ compared to $\mathrm{Pd}(111)$, whereas the $\mathrm{Cu}$ monolayer is expanded by $5.5 \%$ in comparison to clean $\mathrm{Cu}(111)$. In general, a laterally compressed metallic surface is predicted to be less reactive than the unstrained one. ${ }^{1-6}$ Density functional theory (DFT) sixdimensional dynamics calculations showed that the dissociative adsorption of $\mathrm{H}_{2}$ on the $\mathrm{ML} \mathrm{Pd} / \mathrm{Ru}(0001)$ is an activated process with a threshold of $\sim 130 \mathrm{meV} .{ }^{47}$ Moreover, in order to analyze separately the role of surface strain, the authors have carried out similar DFT calculations for the pure $\operatorname{Pd}(111)$ surface with lateral lattice constants identical to that of $\mathrm{Ru}(0001)$. For a 3\% laterally compressed $\operatorname{Pd}(111)$ surface, the top site is the most reactive one and the barrier height is only $20 \mathrm{meV}$, which means that it is practically non-activated. This result shows that the reactivity to $\mathrm{H}_{2}$ for the ML $\mathrm{Pd} / \mathrm{Ru}(0001)$ cannot be completely explained in terms of strain only, but it is also due to the electronic coupling with the $\mathrm{Ru}(0001)$ substrate, specifically Pd donates charge to the $\mathrm{Ru}(0001)$ substrate and, then, becomes less reactive. For this system, both the $\mathrm{Pd} / \mathrm{Ru}$ interface-induced electronic effects and the compressive surface strain produce a downshift of the d-band center which 
makes the system less reactive than $\mathrm{Pd}(111)$. The reported sticking probability of 0.05 with the background hydrogen ${ }^{40}$ is very much reduced compared to the one of the clean $\mathrm{Pd}(111)$ surface and is thus in very good agreement with the mentioned calculations. The $\mathrm{H}_{2}$ sticking value is lower than the one on clean $\mathrm{Ru}(0001)$ by a factor of $\sim 4$, which allows us to exclude the presence of clean $\mathrm{Ru}$ islands in the Pd monolayer.

For the expanded ML Cu/Ru(0001), the data measured at $100 \mathrm{~K}$ (Fig. 2) suggest a strong electronic coupling between the $\mathrm{Cu}$ overlayer and the $\mathrm{Ru}$ substrate, since the $\mathrm{O}_{2}$ sticking probability follows the same trend, both in the low and high kinetic energy regimes as the corresponding curve for clean $\mathrm{Ru}(0001)$. A similar behaviour of the sticking probability has been reported for measurements performed at $300 \mathrm{~K},{ }^{36}$ which suggests dissociative sticking of $\mathrm{O}_{2}$ on the $\mathrm{ML} \mathrm{Cu} / \mathrm{Ru}(0001)$ surface.

In the case of the ML $\mathrm{Pd} / \mathrm{Ru}(0001)$, the dynamics is completely different, since the $\mathrm{O}_{2}$ sticking probability monotonically decreases with the incident energy at $100 \mathrm{~K}$, whereas no sticking of $\mathrm{O}_{2}$ is observed at $300 \mathrm{~K}$. This behaviour is consistent with the molecularly adsorbed oxygen. This is supported by the thermal desorption measurements presented in Fig. 4, which show an $\mathrm{O}_{2}$ desorption peak at ca. $145 \mathrm{~K}$. After a mild annealing, the clean ML $\mathrm{Pd} / \mathrm{Ru}(0001)$ surface is recovered. A previous study of $\mathrm{O}_{2}$ adsorption on $\mathrm{Pd}(111)$ has shown that molecular desorption occurs at $150 \mathrm{~K}$ and $200 \mathrm{~K} .{ }^{44}$ Our present study shows that the first of these peaks is also present on the $\mathrm{ML} \mathrm{Pd} / \mathrm{Ru}(0001)$, whereas no evidence has been found for the existence of the second peak. This may be an indication of weaker $\mathrm{O}_{2}$ bonding on the the ML Pd/Ru(0001) surface in comparison to clean $\operatorname{Pd}(111)$. A weaker adsorption strength on the 1 ML Pd film compared to $\operatorname{Pd}(111)$ has been also reported for the $\mathrm{CO}$ adsorption. ${ }^{26} \mathrm{~A}$ similar behaviour has been observed on the $\mathrm{Pt} / \mathrm{Ru}(0001)$ system, for which the molecular chemisorption of oxygen is completely suppressed for the Pt monolayer. ${ }^{6}$ For 2 MLs of Pt, oxygen chemisorbs molecularly, but no dissociation occurs. Thermal desorption measurements show that oxygen desorption sets in prior to dissociation. The dissociation of $\mathrm{O}_{2}$ is only observed for 3 MLs of Pt, where annealing leads to dissociation, like on $\operatorname{Pt}(111){ }^{6}$

The high reactivity of $\mathrm{PdRu} / \mathrm{Ru}(0001)$ surface alloys toward $\mathrm{H}_{2}$ was already known. ${ }^{11}$ Those authors showed that $\mathrm{PdRu} / \mathrm{Ru}(0001)$ surface alloys can be prepared with different Pd coverages. The deuterium adsorption probability was found to be independent from Pd concentration in the surface alloy, and almost identical within the experimental error to the one measured on clean $\mathrm{Ru}(0001)$, even for such a high Pd concentration as in $\mathrm{Pd}_{0.95} \mathrm{Ru}_{0.05} / \mathrm{Ru}(0001){ }^{11}$ The reactivity was substantially reduced when the Ru surface was fully covered by a complete ML of Pd. This suggests that only a small percentage of $\mathrm{Ru}$ atoms present on the surface are required to change the reactivity of the surface drastically and dissociate efficiently $\mathrm{H}_{2}$ molecules. This might be due to the existence of a short-living, mobile molecular precursor state, in which the $\mathrm{Ru}$ impurities become scattering centers, leading to an enhanced probability for dissociative adsorption. For the $\mathrm{PdRu} / \mathrm{Ru}(0001)$ surface alloy, DFT calculations have shown that its high reactivity is actually due to an environment-driven mechanism, which makes Ru atoms surrounded by Pd atoms even more reactive than in pure $\mathrm{Ru}(0001) .^{40}$ Our current results show that a similar increase in reactivity occurs for $\mathrm{O}_{2}$ molecules. Both at $100 \mathrm{~K}$ and $300 \mathrm{~K}$, the reactivity is highly enhanced and resembles the one measured for clean $\mathrm{Ru}(0001)$. Especially remarkable is the effect observed at $300 \mathrm{~K}$. Whereas the $\mathrm{ML} \mathrm{Pd} / \mathrm{Ru}(0001)$ system was found to be inert to $\mathrm{O}_{2}$ adsorption, the $\mathrm{Pd}_{0.95} \mathrm{Ru}_{0.05} / \mathrm{Ru}(0001)$ surface alloy exhibits a very high reactivity. Moreover, thermal desorption measurements suggest that the adsorption dynamics is very different on the two systems. $\mathrm{No}_{2}$ desorption peak was observed below 200 $\mathrm{K}$ from the $\mathrm{Pd}_{0.95} \mathrm{Ru}_{0.05} / \mathrm{Ru}(0001)$ surface alloy, suggesting that the $\mathrm{O}_{2}$ molecules dissociate onto this surface due to the presence of the few available $\mathrm{Ru}$ atoms, while the adsorption is molecular on the ML $\mathrm{Pd} / \mathrm{Ru}(0001)$ system.

\section{CONCLUSIONS}

Initial sticking probabilities have been measured for $\mathrm{O}_{2}$ molecules on the monolayer $\mathrm{Pd} / \mathrm{Ru}(0001)$. The system shows very different properties compared to the clean $\mathrm{Ru}(0001)$ and $\operatorname{Pd}(111)$ surfaces. For the compressed Pd monolayer, a lower reactivity than on $\mathrm{Pd}(111)$ is observed for $\mathrm{O}_{2}$ molecules, due to both the compressive strain and the electronic interaction with the $\mathrm{Ru}$ substrate producing a downshift of the d-band center, as predicted also for $\mathrm{H}_{2}$ molecules. ${ }^{47}$ No sticking of $\mathrm{O}_{2}$ could be detected at $300 \mathrm{~K}$. Thermal desorption data suggest that the sticking observed at $100 \mathrm{~K}$ is due to the molecular adsorption of $\mathrm{O}_{2}$. Surprisingly, a very small amount of $\mathrm{Ru}$ atoms left on the $\mathrm{Pd}_{0.95} \mathrm{Ru}_{0.05} / \mathrm{Ru}(0001)$ surface efficiently dissociate $\mathrm{O}_{2}$ molecules, with initial sticking probabilities very close to those observed on the clean $\mathrm{Ru}(0001)$ surface. Theoretical work is needed to clarify whether the high reactivity observed for $\mathrm{O}_{2}$ on the PdRu surface alloy is also due to an environment-driven mechanism, as already reported for the case of $\mathrm{H}_{2}$ adsorption on the same system, ${ }^{40}$ or to a different effect.

\section{ACKNOWLEDGMENTS}

This work has been supported by Project No. FIS201567367-C2-1-P and FrontNanoMagnet. D.F. acknowledges financial support from the Spanish Ministry of Economy and Competitiveness, through the "María de Maeztu" Programme for Units of Excellence in R\&D (No. MDM-2014-0377).

This work is dedicated to the memory of our mentor and colleague Karl-Heinz Rieder, pioneer in so many areas of surface science.

\footnotetext{
${ }^{1}$ M. Gsell, P. Jakob, and D. Menzel, Science 280, 717 (1998).

${ }^{2}$ M. Mavrikakis, B. Hammer, and J. K. Nørskov, Phys. Rev. Lett. 81, 2819 (1998).

${ }^{3}$ Y. Xu and M. Mavrikakis, Surf. Sci. 494, 131 (2001).

${ }^{4}$ S. Sakong and A. Gross, Surf. Sci. 525, 107 (2003).

${ }^{5}$ A. Schlapka, M. Lischka, A. Gross, U. Kraesberger, and P. Jakob, Phys. Rev. Lett. 91, 016101 (2003).

${ }^{6}$ P. Jakob, A. Schlapka, and P. Gazdzicki, J. Chem. Phys. 134, 224707 (2011).

${ }^{7}$ A. Schlapka, M. Lischka, A. Gross, U. Kraesberger, and P. Jakob, Phys. Rev. B 77, 193408 (2008).

${ }^{8}$ J. A. Rodriguez, Surf. Sci. Rep. 24, 223 (1996).

${ }^{9}$ J. G. Chen, C. A. Menning, and M. B. Zellner, Surf. Sci. Rep. 63, 201 (2008).

${ }^{10}$ A. Gross, J. Phys.: Condens. Matter 21, 084205 (2009).
} 
${ }^{11}$ H. Hartmann, T. Diemant, A. Bergbreiter, J. Bansmann, H. E. Hoster, and R. J. Behm, Surf. Sci. 603, 1439 (2009).

${ }^{12}$ H. Hartmann, T. Diemant, J. Bansmann, and R. J. Behm, Surf. Sci. 603, 1456 (2009).

${ }^{13}$ T. Diemant, H. Rauscher, and R. J. Behm, J. Phys. Chem. C 112, 8381 (2008).

${ }^{14}$ T. Diemant, A. Bergbreiter, J. Bansmann, H. E. Hoster, and R. J. Behm, ChemPhysChem 11, 3123 (2010).

${ }^{15}$ H. L. Tierney, A. E. Baber, J. R. Kitchin, and E. C. H. Sykes, Phys. Rev. Lett. 103, 246102 (2009).

${ }^{16}$ D. Farías, M. Minniti, A. Al Taleb, and R. Miranda, Z. Phys. Chem. 227, 1 (2013).

${ }^{17}$ I. M. N. Groot, A. W. Kleyn, and L. B. F. Juurlink, Angew. Chem., Int. Ed. 50, 5174 (2011).

${ }^{18}$ I. M. N. Groot, A. W. Kleyn, and L. B. F. Juurlink, J. Phys. Chem. C 117(18), 9266 (2013).

${ }^{19}$ S. Blomberg, J. Zetterberg, J. Zhou, L. R. Merte, J. Gustafson, M. Shipilin, A. Trinchero, L. A. Miccio, A. Magana, M. Ilyn, F. Schiller, J. E. Ortega, F. Bertram, H. Grönbeck, and E. Lundgren, ACS Catal. 7, 110 (2017).

${ }^{20}$ A. L. Walter, F. Schiller, M. Corso, L. R. Merte, F. Bertram, J. Lobo-Checa, M. Shipilin, J. Gustafson, E. Lundgren, A. X. Brion-Rios, P. CabreraSanfelix, D. Sanchez-Portal, and E. J. Ortega, Nat. Commun. 6, 8903 (2015).

${ }^{21}$ P. Nieto, E. Pijper, D. Barredo, G. Laurent, R. A. Olsen, E. J. Baerends, G. J. Kroes, and D. Farías, Science 312, 86 (2006).

${ }^{22}$ J. Behler, B. Delley, S. Lorenz, K. Reuter, and M. Scheffler, Phys. Rev. Lett. 94, 036104 (2005).

${ }^{23}$ L. Osterlund, I. Zoric, and B. Kasemo, Phys. Rev. B 55, 15452 (1997).

${ }^{24}$ C. Carbogno, J. Behler, A. Gross, and K. Reuter, Phys. Rev. Lett. 101, 096104 (2008).

${ }^{25}$ C. Carbogno, J. Behler, K. Reuter, and A. Gross, Phys. Rev. B 81, 035410 (2010).

${ }^{26}$ C. Park, Surf. Sci. 203, 395 (1988).

${ }^{27}$ R. A. Campbell, J. A. Rodriguez, and D. W. Goodman, Phys. Rev. B 46, 7077 (1992).

${ }^{28}$ N. Rougemaille, F. El Gabaly, R. Stumpf, A. K. Schmid, K. Thurmer, N. C. Bartelt, and J. de la Figuera, Phys. Rev. Lett. 99, 106101 (2007).
${ }^{29}$ B. Santos, J. M. Puerta, J. I. Cerda, T. Herranz, K. F. McCarty, and J. de la Figuera, New J. Phys. 12, 023023 (2010).

${ }^{30}$ E. Golfetto, A. Baraldi, M. Pozzo, D. Alfe, A. Sala, P. Lacovig, E. Vesselli, S. Lizzit, G. Comelli, and R. Rosei, J. Phys. Chem. C 114, 436 (2010).

${ }^{31}$ D. A. King and M. G. Wells, Proc. R. Soc. A 339, 245 (1974).

${ }^{32}$ P. Nieto, D. Barredo, D. Farías, and R. Miranda, J. Phys. Chem. A 115, 7283 (2011).

${ }^{33}$ P. Nieto, D. Farías, R. Miranda, M. Luppi, E. J. Baerends, M. F. Somers, M. J. T. C. van der Niet, R. A. Olsen, and G. J. Kroes, Phys. Chem. Chem. Phys. 13, 8583 (2011).

${ }^{34}$ D. Farías and K. H. Rieder, Rep. Prog. Phys. 61, 1575 (1998).

${ }^{35} \mathrm{G}$. Scoles, Atomic and Molecular Beam Methods (Oxford University Press, New York, 1992), Vol. 1.

${ }^{36}$ M. Minniti, D. Farías, P. Perna, and R. Miranda, J. Chem. Phys. 137, 074706 (2012).

${ }^{37}$ D. Farías and R. Miranda, Prog. Surf. Sci. 86, 222 (2011).

${ }^{38}$ B. Poelsema and G. Comsa, Scattering of Thermal Energy Atoms from Disordered Surfaces, Springer Tracts in Modern Physics (Springer, Berlin, 1989), Vol. 115.

${ }^{39}$ A. Cebollada, R. Miranda, C. M. Schneider, P. Schuster, and J. Kirschner, J. Magn. Magn. Mater. 102, 25 (1991).

${ }^{40}$ M. Ramos, M. Minniti, C. Díaz, D. Farías, R. Miranda, F. Martín, A. E. Martínez, and H. F. Busnengo, Phys. Chem. Chem. Phys. 15, 14936 (2013).

${ }^{41}$ P. Sjovall and P. Uvdal, Chem. Phys. Lett. 282, 355 (1998).

${ }^{42}$ M. C. Wheeler, D. C. Seets, and C. B. Mullins, J. Chem. Phys. 105, 1572 (1996).

${ }^{43}$ W. J. Mitchell, J. Xie, K. J. Lyons, and W. H. Weinberg, J. Vac. Sci. Technol., A 12, 2250 (1994).

${ }^{44}$ X. Guo, A. Hoffman, and J. T. Yates, Jr., J. Chem. Phys. 90, 5787 (1989).

${ }^{45}$ B. Hammer, Y. Morikawa, and J. K. Nørskov, Phys. Rev. Lett. 76, 2141 (1996).

${ }^{46}$ B. Hammer and J. K. Nørskov, Surf. Sci. 343, 211 (1995).

${ }^{47}$ G. Laurent, H. F. Busnengo, P. Rivière, and F. Martín, Phys. Rev. B 77, 193408 (2008). 